\title{
Near-Death Experiences and the Mind-Body Problem
}

\author{
Mark B. Woodhouse \\ Department of Philosophy \\ Georgia State University
}

When the tension between the conceptual and the empirical becomes too great, that is, when old theories and new evidence appear not to fit each other, the scientific community divides roughly into two camps. The first group more or less accepts the evidence, usually with certain qualifications, and goes in search of a theory or conceptual framework within which to fit it. The result is sometimes a paradigm shift. The second group stands with the accepted theoretical framework, again usually with some qualifications, and rejects or explains away the alleged facts on the grounds that they are incompatible with what we already know to be the case.

Although the above description is an oversimplification, it nevertheless applies straightforwardly to current controversies surrounding near-death phenomena. A small number of scientists and medical doctors accept the phenomena for what they are minimally purported to be by numerous subjects, namely, the temporary experience of being out of one's body, although further interpretations given by those subjects are open to critical scrutiny. 1 We shall call this the objectivist view. The other group, by far the great majority, rejects the out-of-body interpretation, giving instead their own subjectivist or "hallucinatory" explanations which take a variety of forms. Which interpretation is correct?

A number of perspectives come into play. It is the biomedical scientist's job to propose physiological explanations and to examine the adequacy of various hallucinatory accounts. It is the psychologist's job to research the characteristics of near-death experiences and to assess critically those variables that bear upon the validity of the research. And it is the philosopher's job to examine the logical adequacy of competing arguments and the conceptual and methodological issues that underlie those arguments. My purpose in this paper is to examine the debate in light of several questionable assumptions regarding the mind-body problem.

Let me state at the outset that my sympathies are with the objectivist interpretation, although $I$, too, have my reservations about individual accounts, particularly those pertaining to the transcendental aspect of the experience, e.g., that so-and-so saw the Virgin 
Mary. Hallucinatory-type explanations simply do not fit the growing body of data or else appear hopelessly ad hoc. For example, they do not account for the patient's knowledge of events in the operating room. In addition, characteristics which define hallucinations are missing in NDEs. Moreover, at least one cardiologist claims to have correlated NDEs with flat EEGs, a claim which, if born out, would appear to rule out the possibility of hallucinations. 2 Thus, I am concerned with the assumptions that mistakenly may channel the critic of NDEs into an unworkable subjectivism, assumptions that when set straight may help render more acceptable an objectivist interpretation. In a limited fashion we may be able to have our cake and eat it too when it is seen that NDEs and an enlightened materialism are perfectly compatible.

\section{I}

Although in the West mind-body dualism is traceable to both Greek and Egyptian cultures, its modern formulation stems from Descartes. Matter is solid (or composed of tiny indestructible "corpuscles"), visible, extended, measurable, discontinuous, and inert or passive. Mind is fluid, invisible, extensionless, at best only indirectly measurable through its manifestations in physical substance, continuous (though supporting distinguishable mental states such as sensations and thoughts), and active, e.g., volitional. Neither is reducible to the other, and each interacts in some poorly understood way with the other. This much with significant variations is affirmed by dualists, with materialists rejecting mind and urging that at the time of death there is nothing "left over" to survive the body.

To continue with our brief conceptual cartography, dualism is logically entailed by, say, Christian theism, but the reverse is not true; being a dualist and a believer in survival doesn't in itself entail any particular religious commitment. On the other hand, materialism, which is the philosophical credo of most scientists qua scientists, is usually held to be logically incompatible with religion, particularly the doctrine of immortality.

Many critics of NDEs may reject them, I think, because they believe that such phenomena, taken literally, are incompatible with scientific materialism and the foundations of medical science in particular. Somehow, one just can't be a doctor and suppose that the "real person" is the ghost in the machine, not the machine itself. The issue is further clouded by the fact that dualism is usually assumed to be the only alternative to materialism and is somehow associated with being anti-scientific, "soft-headed," sympathetic to occult 
phenomena, and the like. Thus because dualism is associated with an objectivist interpretation of NDEs, scientific materialism seems to require the subjectivist interpretation.

But is it really required? Actually, there are two questions to consider: (1) Does an objectivist interpretation of NDEs logically preclude commitment to some form of materialism? (2) Does such an interpretation entail a form of dualism? The answer to each is negative. If dualism and materialism are incompatible, then whatever is logically consistent with the latter cannot possibly be entailed by the former. Our task then becomes that of showing how an objectivist interpretation of NDEs is compatible with materialism. Our account will also be strengthened by showing how several dualist considerations can be made to fit the emerging materialist model.

Materialism traditionally connotes a commitment to "matter," the physical stuff of which the furniture of the world is made. A scientific materialist ought to hold that the ultimate stuff of the universe is what physics in broad outline says it is. And anyone following the rise of the "new physics" has watched matter become increasingly dematerialized of its traditional properties in favor of energy and its numerous forms. The story is by now a familiar one, particularly to readers of Capra (1975), Zukav (1979), Bohm (1978), Heisenberg, etc., although the impact has yet to be felt in public education. ${ }^{3}$ Briefly summarized, the picture unfolds as follows. Matter and energy are not merely intertranslatable one to the other as "corealities." Rather, matter is (but a form of) energy, and the latter is the fundamental reality. Subatomic particles are functions of compressed energy, "knots" within fields where vibratory interaction is very intense. The perception of solidity "out there" is a function of phase-locking of different field vibrations. Energy is active, and the being of material objects is constituted by their becoming. The appearance of physical discontinuity is (always?) grounded in the reality of an underlying continuum of energy. As Einstein (1961) himself summarizes: "There is no place in this new kind of physics for both the field and matter, for the field is the only reality." It would be intellectually dishonest to portray the preceding as established fact. Yet many of the best minds in the field have made it clear that this is where we are headed, at least in broad outline. Thus while I have not seen the phrase in print, a commitment to "energymaterialism" now ap pears very much in order.

What are the implications of energy-materialism for NDEs? To 
begin, the idea of emanations of energy from a "nearly dead" body should not surprise us on theoretical grounds. The factual question is thus left open as to whether such departures actually take place, and an objectivist interpretation cannot be ruled out on a priori grounds. There are two directions we may take in visualizing such a departure. We may suppose that this energy results from a corresponding reduction in mass, although, of course, the amount of mass involved need only be fractional given the potentially large amount of energy packed into even a drop of water. One test consequence of this approach would be to engage in some sophisticated measurements of possible mass reduction at the time of "bodily departure." An alternative model involves our supposing the existence of a secondary body of energy that exists in the same general space as the physical body but is not co-extensive with it, i.e., does not necessarily stop at the skin's surface. This involves nothing more conceptually disturbing than the supposition that several types of energy systems can occupy the same general region of space. Even now, strong and weak nuclear, gravitational, and electromagnetic forms of energy are to be found within the limits of my skin. Thus an objectivist interpretation of NDEs and energy-materialism are conceptually compatible.

Let us explore a bit further the implications of the altcrnate-body model. Bearing in mind that what is crucial to science is not its metaphysics, e.g., "To be is to be material," but its epistemology, e.g., "To be is to be detectable," we have to suppose that this body of energy vibrating at higher frequencies is at least in principal detectable or measurable in some fashion, even if the technology is not yet available to us. Given this assumption, moreover, we must then determine if that energy-body is one of the four (now three) known basic forms of energy or whether it constitutes a fifth (fourth) form unique to living organisms.

There is already much pioneering work in this general area conducted independently of NDE research, e.g., by Burr (1973), Osis and McCormick (1980), Moss (1979), etc.4 I draw attention particularly to the work of the Japanese physician, Hiroshi Motoyama (1980), whose belief in the existence of alternative energy-bodies is buttressed by his development of a computerized instrument for measuring energy imbalance along acupuncture meridians and between chakras (energy centers postulated by various systems of Yoga) connecting such bodies. His instrument is currently used in numerous hospitals throughout Japan as an important diagnostic tool. 5 While progress is slow and "proof," if any, far away, there are nonetheless potentially viable models available to us. Energy-bodies needn't be only the stuff of pipe dreams. 
Of course, the difficulties loom large in doing significant research to detect such normally invisible entities. For example, Kirlian photographers repeatedly have photographed "phantom limbs" of plants. Now if there are phantom limbs, there can be phantom bodies remaining when the original "physical" model is removed. The catch is that the picture must be taken several seconds after the removal of the original and that only about 1 in 400 photographs is successful in producing this effect, for reasons not understood. How such procedures can be applied effectively to humans, much less to those undergoing spontaneous NDEs, remains to be seen. Yet with the a priori objections removed and research possibilities open to us (which are not the job of the philosopher to speculate on), there seems every reason to push ahead and put the objectivist interpretation of NDEs to the test.

\section{III}

And what is the dualist to make of energy-materialism? He is naturally inclined to accept an objectivist interpretation of NDEs, since survival is already built in to his theoretical framework. Proceeding with the same assumption as the typical materialist, viz., that solid physical stuff or nonphysical stuff are the only viable options for minds, the weakness of standard materialism in accounting for NDEs becomes the dualist's potential trump card. Energy-materialism, however, changes much of this. Why? Because many of the categorical descriptions of the dualist's mind or spirit are applicable to energy. Energy, like mind, is invisible, fluid, diaphanous, active, lacking rigid (spatial) boundaries, and capable of existing independently of matter (which is after all but one of its many forms). The fact that we cannot directly "see" others' experiences no matter how powerful our neural scanning devices-a fact that led a number of brain researchers, such as Eccles and Sherrington, to espouse dualismis hardly evidence for dualism if it is perfectly compatible with energy-materialism; we do not, after all, "see" energy either. I should emphasize that the problem for the dualist is rather severe in this regard. For it is not that he is now merely without certain evidence that would have tended to strengthen his position. Rather, the categories that enable him to uniquely define his position are becoming so sparse that he stands in danger of retaining little of substance to defend; his territory is being usurped.

Let me elaborate on this "vanishing point" hypothesis in more detail. Patients who reportedly leave their bodies in operating rooms often describe with great precision the goings-on in the room during 
their near-death experience. Moreover, their "observations" are frequently such that they could only have been made from a point of view apart from the body. Now a point of view is a point in space, yet non-spatiality is a defining characteristic of the dualist's mind. Hence, the point of view in question cannot be that of a spiritual entity. The irony of this is that while the dualist is normally able to rely upon the body to provide the point of view, NDEs that one would expect to strengthen his case turn out instead to undermine it, i.e., the basis for a point of view is lost.

The dualist may still take the offensive, however, in pointing to a serious problem for the energy-materialist. Suppose we are successful in detecting and measuring in some fashion some energy or bioplasmic body that can separate from its physical counterpart. On what grounds can we then identify this body with the experiences, memories, and personality of the person who underwent an NDE? How do we know that this etheric double is Jones? If by "identify" we mean somehow "observe Jone's emotions in an energy field," then of course we cannot. But this objection is hardly telling against the energy-materialist since it is precisely the problem the dualist faces, too. Experiences are not visibly identifiable with anything, energy, spirit, or matter. Besides, the energy-materialist may point out, when we look for Jones's memories, etc., we should be looking for structure and function, not for little "things" floating in space. Analogously, we do not "see" information in a computer. The most promising structuralist account in this regard is given in Karl Pribram's (1978) "holographic" model of information processing.

The dualist may also urge that, even if we are successful in our search for an energy body, the most this could strictly demonstrate is that the departure of the mind/soul is "correlated" with an object that now falls within the purview of scientific investigation. Thus, for example, Seymon Kirlian (1961) once described his photographic process as involving "the transformation of non-electrical properties of the photographed subject into electrical ones via the motion of a field. ..." Are these nonelectrical properties possibly those of a nonphysical entity? The way appears open for the dualist to argue in a systematic fashion that the mind manifests itself empirically under certain conditions but is not an empirical entity in itself. In this way dualism may be preserved no matter what strides are made in science. The cost of preservation, however, is high, namely, increasing lack of intelligibility. To reiterate an earlier conclusion, as more of the characteristics typical of the dualist's "mind" are absorbed by the energy-materialist, the former is left with a conceptually vanishing 
point. After all, the kind of entity $\mathrm{X}$ is, is normally determined by the characteristics it manifests. 6

Despite the proceding arguments, a theological retreat is open to the dualist. This retreat consists in insisting upon the distinction between, say, the Christian "soul" and our ordinary minds and experiences-a distinction that I have blurred in this paper. Thus a Christian theist might hold out for an immortal, nonphysical soul while conceding my case for energy-materialism with respect to the mind. While such a move is certainly a logical possibility, the price of doing so is very high. For everything that is psychologically or morally descriptive of me, anything that could justify a "final judgment," and every part of me the survival of which I would care about, is wrapped up directly or indirectly with the mind, my psychological self. The soul that leaves all this behind, so to speak, cannot be said to be me in any meaningful sense. It is no more me than anyone else. The future of such contentless stuff, be it the original essence of the Divine or not, would from a personal point of view be of no more concern than, say, the future of a pint of my blood subject to eternal but lethal doses of radiation in some far away place. In short, the motivation to take seriously a doctrine of salvation collapses. 7 Such, it seems to me, is the high price to be paid.

At the other end of the metaphysical spectrum, the traditional materialist may object that all the talk of energy-bodies concedes too much to the dualist. Indeed, the materialist is being asked to modify his model of human nature as much as if not more than the dualist. Our request may be premature, but it is neither unreasonable nor incoherent if we take the evidence from theoretical physics and NDEs seriously. Energy-materialism is a mediating proposal in terms of which both traditional materialism and dualism may be seen as abstractions. The former hypostatizes the more stable forms of energy as matter, the latter hypostatizes its more fluid diaphanous forms as mind. Each may be faulted for transforming differences of degree into those of principle, that is, into distinct metaphysical models. In fact, my energy-materialism might better be called "energy-monism" along the spectrum of which the materialist takes one and the dualist takes two distinctive slices as reality. The final verdict on NDEs is far from in. But when it comes, it should not be predicated upon the assumption of a set of misguided and extreme metaphysical models of mind.

\section{NOTES}

1. The literature describing NDEs is becoming voluminous. Two ex- 
tensive critical examinations are Osis and Haraldsson (1977) and Ring (1980).

2. An excellent discussion of the merits and weaknesses of these interpretations is found in The Journal of Nervous and Mental Disease, 1980, Vol. 168, No. 5, in articles by Rodin, Schnaper, Sabom, Moody, Stevenson, and Ring.

3. Cf., for example, Fritjof Capra (1975) and Gary Zukav (1979). Some of the more startling applications and implications are discussed in interviews with David Bohm (1978) and Karl Pribram (1978).

4. With the exception of Osis's work (which was described to me personally) the concepts of "life-fields," "auras," and secondary "bioplasmic" energy bodies are discussed in Mishlove (1975). See also Burr (1973), Alvarado (1980), and Tiller (1974).

5. Motoyama (1978). I am indebted to Kenneth Ring for bringing Motoyama's work to my attention.

6. "Privacy" may well remain a problem here, i.e., as an irreducible and defining feature of the mental. Without examining the issue in detail, let me indicate that to support my account, I would attempt to show that the difference between the direct, priviledged knowledge each of us has of our own experience and the "public" knowledge of our bodies implies no more than a difference of degree between energy and matter.

7. The philosophical issues and arguments surrounding this claim are more extensively examined in Woodhouse (1970).

\section{REFERENCES}

Alvarado, C. The physical detection of the astral body: an historical perspective. Theta, $1980,8(2), 4-7$.

Bohm, D. The enfolding-unfolding universe. Re-Vision, 1978, 1(3/4), 24-52.

Burr, H. S. The Fields of Life. New York: Ballentine, 1973.

Capek, M. The Philsophical Impact of Contemporary Physics. New York: Van Nostrand, 1961.

Capra, F. The Tao of Physics. Berkeley: Shambhala, 1975.

Kirlian, S. D. Photography and visual observations by means of highfrequency currents. Journal of Scientific and Applied Photography, $1961,6,397-403$.

Mishlove, J. The Roots of Consciousness. New York: Random House, 1975.

Moss, T. The Body Electric. Los Angeles: J. P. Tarcher, 1979. 
Motoyama, H. Science and the Evolution of Consciousness. Brookline, Mass.: Autumn Press, 1978.

Osis, K., and Haraldsson, E. At the Hour of Death. New York: Avon, 1977.

Osis, K., and McCormick, D. Kinetic effects at the ostensible location of an out-of-body projection during perceptual testing. Journal of the American Society for Psychical Research, 1980, 74, 319-329.

Probram, K. What the Fuss is All About. Re-Vision, 1978, 1(3/4), 14-19.

Ring, K. Life at Death. New York: Coward, McCann \& Geoghegan, 1980.

Tiller, W. Energy fields and the human body. In J. White (ed.), Frontiers of Consciousness. New York: Julian Press, 1974, 229-242.

Woodhouse, M. Selves and minds. Religious Studies, 1970, 6, 263-273. Zukav, G. The Dancing Wu Li Masters. New York: William Morrow, 1979.

Requests for reprints to:

Mark B. Woodhouse

Department of Philosophy

Georgia State University

University Plaza

Atlanta, Georgia 30303 